\title{
Parametric study of automotive composite bumper beams subjected to frontal impacts
}

\begin{abstract}
The parametric study of automotive composite bumper beam subjected to frontal impact is presented and discussed in this paper. The aim of this study is to analyze the effect of steel and composite material on energy absorption of automotive front bumper beam. The front bumper beams made of e-glass/epoxy composite and carbon epoxy composite are studied and characterized by impact modeling using LS-DYNA V971, according to United States New Car Assessment Program (US-NCAP) frontal impact velocity and based on European Enhanced Vehicle-safety Committee. The most important variable of this structure are- mass, material, and Specific Energy Absorption (SEA). The results are compared with bumper beam made of mild steel. Three types of materials are used in the present study which consists of mild steel as references material, Aluminum AA5182, E-glass/epoxy composite and carbon fiber/epoxy composite with three different fiber configurations. The beams were subjected to impact loading to determine the internal energy and SEA and to reduce mass of the conventional bumper beam. The in-plane failure behaviors of the composites were evaluated by using Tsai $\mathrm{Wu}$ failure criterion. The results for the composite materials are compared to that of the reference material to find the best material with highest SEA. LSDYNA Finite Element Analysis software was used. The results showed that carbon fiber/epoxy composite bumper can reduce the bumper mass and has highest value of SEA followed by glass fiber/epoxy composite.
\end{abstract}

Keyword: Front bumper beam; Internal energy; Specific energy absorption; E-glass/epoxy composite; Carbon/epoxy composite 